SHORT REPORT

\title{
Can salivary lead be used for biological monitoring of lead exposed individuals?
}

\author{
D Koh, V Ng, L H Chua, Y Yang, H Y Ong, S E Chia
}

Occup Environ Med 2003;60:696-698

Background: Measurement of blood lead (BPb) is the usual method for biomonitoring of persons exposed to inorganic lead.

Aim: To explore the use of salivary lead (SPb) as an alternative.

Methods: $\mathrm{BPb}$ and $\mathrm{SPb}$ levels were measured in a group of 82 lead exposed adults.

Results: The mean BPb of the workers was $26.6 \mu \mathrm{g} / \mathrm{dl}$ (SD 8.6 , range $10-48$ ) and the mean SPb level $0.77 \mu \mathrm{g} / \mathrm{dl}$, or $3 \%$ of the $\mathrm{BPb}$ level. As the $\mathrm{SPb}$ distribution was skewed, logarithmic transformation was performed to normalise the distribution. A bivariate scattergram of $\mathrm{BPb}$ and $\log \mathrm{SPb}$ $(r=0.41, p=0.00)$ had a line of best fit expressed as BPb $=29.7+8.95 \log \mathrm{SPb}$. The relation of $\log \mathrm{SPb}$ and $\mathrm{BPb}$ was stronger among non-smokers $(r=0.42)$ compared to smokers $(r=0.3)$; and among those without a medical condition $(r=0.44)$. Multiple linear regression analysis (fitting smoking and medical condition into the model) yielded an $R$ of 0.54 , and an adjusted $R^{2}$ of 0.26 .

Conclusion: The study findings do not support the use of $\mathrm{SPb}$ for biomonitoring at $\mathrm{BPb}$ levels ranging from 10 to 50 $\mu \mathrm{g} / \mathrm{dl}$.

M any toxins and their metabolites are excreted in saliva, and salivary levels can reflect levels in the other body compartments. ${ }^{1}$ Previously, Pan $^{2}$ showed a good correlation between salivary and blood lead $(r=0.72)$ among adult males. The subjects were divided into four groups of 88,114 , 31, and 33, with increasing group mean values of blood lead (BPb) $(18,27,67$, and $82 \mu \mathrm{g} / \mathrm{dl})$. At BPb levels $>50 \mu \mathrm{g} / \mathrm{dl}$, salivary lead $(\mathrm{SPb})$ levels increased almost exponentially. The correlation coefficient $(r)$ for blood and log salivary lead was 0.8 . The $r$ for $\mathrm{BPb}$ and $\mathrm{SPb}$ within each of the four groups were unreported.

At low levels of $\mathrm{BPb}$, the relation with $\mathrm{SPb}$ is less clear. A study $^{3}$ of 24 normal subjects with BPb levels of $6-14 \mu \mathrm{g} / \mathrm{dl}$ showed a poor and negative correlation with $\mathrm{SPb}$ levels $(r=-0.186)$. Another study of nine children with BPb levels of $20-60 \mu \mathrm{g} / \mathrm{dl}$, also showed a weak correlation $(r=0.07)$ between $\mathrm{BPb}$ and $\mathrm{SPb} .{ }^{4}$ Lead levels in parotid saliva among 10 adults with BPb levels of $16-33 \mu \mathrm{g} / \mathrm{dl}$ showed poor correlation $(r=0.137)$ with BPb. ${ }^{5}$

In view of these inconsistent results, we studied the relation between $\mathrm{BPb}$ and $\mathrm{SPb}$ in 82 adult lead exposed workers with $\mathrm{BPb}$ levels of $10-50 \mu \mathrm{g} / \mathrm{dl}$.

\section{METHODS}

We studied 82 workers employed in a factory manufacturing a lead based polyvinyl chloride stabiliser. Our institutional review board approved the study, and all the workers gave written informed consent to participate. We collected personal information as well as blood and saliva samples during

\section{Main messages}

- Salivary lead (SPb) was previously reported to be highly correlated with blood lead (BPb) among adults with high $\mathrm{BPb}$, but not among children, or adults with low $\mathrm{BPb}$. There was no standardised method of collecting saliva in the various studies.

- This study of adults with BPb 10-50 ug/dl showed a poor correlation between $\mathrm{SPb}$ and $\mathrm{BPb}(r=0.4)$.

- Using a multivariate model, $\mathrm{SPb}$, smoking status, and medical condition of the subject could only explain $26 \%$ of the variation in $\mathrm{BPb}$.

\section{Policy implication}

- While the idea of using $\mathrm{SPb}$ to monitor individuals exposed to $\mathrm{Pb}$ is attractive, our findings do not support its use for this purpose at BPb levels between 10 and 50 $\mu \mathrm{pg} / \mathrm{dl}$.

routine six monthly statutory medical examinations. We advised workers not to smoke, eat, or drink (except water) for one hour prior to saliva collection. After rinsing their mouth with water thoroughly, a single, unstimulated saliva sample accumulated over five minutes was obtained. We used a Varian Spectrac AA-220 Atomic Absorption Spectrophotometer, a graphite furnace, autosampler, and D2 lamp background corrector for quantitative analysis of lead, in triplicate. External quality control for $\mathrm{BPb}$ was carried out with the National External Quality Assurance Scheme (UK) and the InterLaboratory Comparison Programme (Canada). Data were analysed with SPSS software Base 10.0. ${ }^{6}$ The skewed SPb values were transformed (logarithmic transformation) before further statistical analysis. All p values are two sided and the level of statistical significance is 0.05 .

\section{RESULTS}

All workers who had to undergo statutory medical examinations agreed to participate in the study. All 82 workers were male, with a mean age of 35 years, and were mainly Indians (43\%), Malays (35\%), or Chinese $(21 \%)$. The duration of employment ranged from three months to 20 years. Most workers $(78 \%)$ were in the production department; $53 \%$ were smokers. Eight workers were hypertensive, two were diabetic, and three had other conditions (neurofibromatosis, hepatitis B carrier, thalassaemia).

Abbreviations: $\mathrm{BPb}$, blood lead; SPb, salivary lead 


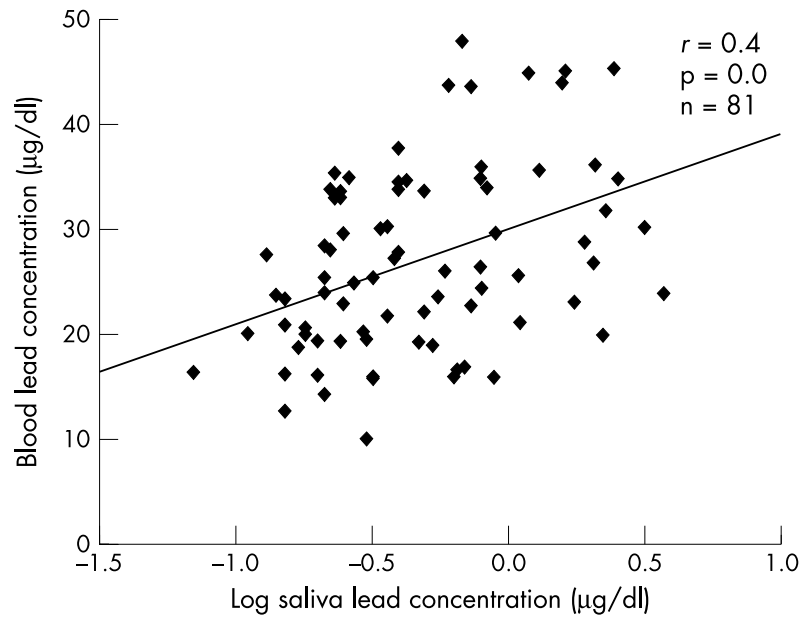

Figure 1 Bivariate scattergram of blood lead and log salivary lead. Blood lead concentration $=29.74+8.95^{*} \log$ salivary lead concentration.

The mean $\mathrm{BPb}$ was $26.6 \mu \mathrm{g} / \mathrm{dl}$ (standard deviation 8.55, range $10-48 \mu \mathrm{g} / \mathrm{dl}$ ). SPb (range $0.07-7.0 \mu \mathrm{g} / \mathrm{dl}$ ) showed a skewed distribution, with one outlier at $7 \mu \mathrm{g} / \mathrm{dl}$. The outlier value was twice as high as the next value, and is likely to represent a contaminated collection sample. This was excluded from subsequent data analysis. Logarithmic transformation was performed for $\mathrm{SPb}$.

A bivariate scattergram of $\log \mathrm{SPb}$ and $\mathrm{BPb}$ showed a correlation coefficient of $0.41(p=0.00)$ (fig 1). The line of best fit is described by the equation:

$$
\mathrm{BPb}=29.74+8.95 * \log \mathrm{SPb}
$$

The bivariate scattergram of log SPb and BPb were also examined in the following groups: subjects without hypertension ( $\mathrm{n}=73, r=0.45, \mathrm{p}=0.00)$; subjects without recorded illness $(\mathrm{n}=68, r=0.44, \mathrm{p}=0.00)$, non-smokers $(\mathrm{n}=38, r=0.42$ $\mathrm{p}=0.008)$, and smokers $(\mathrm{n}=43, r=0.30 \mathrm{p}=0.05)$. Multiple linear regression was done, fitting smoking and medical condition into the model $\left(\mathrm{R}=0.54, \mathrm{R}^{2}=0.28\right.$, adjusted $\left.\mathrm{R}^{2}=0.26\right)$.

\section{DISCUSSION}

The idea of using saliva for biomonitoring is attractive. Its collection is less invasive than venepuncture, and likely to be better accepted by individuals, especially for periodic collections. There is also potential for cost savings, as a skilled technician would not be required to perform the collection.

There are also disadvantages of the determination of salivary lead. At present, there is no standardised method for sampling of saliva or determination of $\mathrm{SPb}$, and no available external quality control programme. There are also no biological limit values for $\mathrm{SPb}$ in comparison to well evaluated limits for $\mathrm{BPb}$.

Specifying the method of saliva collection is important. In earlier studies, ${ }^{23}$ adults first rinsed their mouths with citric acid solution to stimulate salivary flow, followed by rinsing with deionised water, before collection of salivary drool. The method of saliva collection by Fung and colleagues ${ }^{4}$ involved children chewing sugarless gum (which also stimulates salivary flow) prior to collection. In another study, ${ }^{5}$ parotid saliva was collected (after reflex stimulation with orange flavoured lozenges) by a modified double lumen Teflon-Lashley cup.

In this study, unstimulated saliva samples were collected. The method of collection was made as simple and practical as possible under field conditions. Pre-collection instructions - to avoid eating, drinking, or smoking for an hour before collection, and a thorough rinse of the mouth immediately prior to collection-were easily understood and complied with. We carefully supervised each individual saliva collection, as previous reports had suggested that contamination of saliva could be a potential problem. The results showed a fairly uniform distribution of salivary lead among the workers. Only one outlier with an extremely high value was noted. This value is suggestive of contamination during collection, or non-compliance with the pre-collection instructions.

\section{Blood and salivary lead levels}

Plasma lead has two components-protein bound lead and diffusible plasma lead, which is directly excreted into saliva. ${ }^{2}$ At $\mathrm{BPb}<50 \mu \mathrm{g} / \mathrm{dl}$, the concentration of lead appears to be lower in saliva than in blood. Mean SPb was $31 \%$ of the value of mean $\mathrm{BPb}^{4}$ among nine children with a mean $\mathrm{BPb}$ of 42 $\mu \mathrm{g} / \mathrm{dl}$. At a mean BPb of $8.6 \mu \mathrm{g} / \mathrm{dl}$ (range 6-13.6) in 24 adults, $\mathrm{SPb}$ was $56 \%^{3}$ that of $\mathrm{BPb}$. Among 10 normal adults (mean $\mathrm{BPb} 25 \mu \mathrm{g} / \mathrm{dl}$ ), ${ }^{5}$ parotid saliva lead was 13\% of BPb. In Pan's study, ${ }^{2} \mathrm{SPb}$ concentration was $31 \%$ and $16 \%$ of $\mathrm{BPb}$ levels in the groups with mean $\mathrm{BPb}$ of $18 \mu \mathrm{g} / \mathrm{dl}(\mathrm{n}=88)$ and $27 \mu \mathrm{g} / \mathrm{dl}$ $(\mathrm{n}=114)$.

In this study, mean BPb was $26.6 \mu \mathrm{g} / \mathrm{dl}$, while the mean $\mathrm{SPb}$ was $0.77 \mu \mathrm{g} / \mathrm{dl}$, or $2.9 \%$ of $\mathrm{BPb}$. This is the lowest percentage of $\mathrm{SPb}$ expressed as a percentage of $\mathrm{BPb}$ compared to earlier studies, where values ranged from 13\% to 56\%. One reason for this could be that contamination of saliva during collection in this study is much less compared to the earlier studies. In fact, the authors of an earlier study reported that contamination of saliva during collection could be an important issue. ${ }^{5}$ Even $\mathrm{Pan}^{2}$ acknowledged that lack of better correlation between SPb and $\mathrm{BPb}$ could be caused by oral contamination. This made us pay particular attention to proper salivary collection in this study.

At higher BPb levels, $>50 \mu \mathrm{g} / \mathrm{dl}$, SPb concentration was reported to be higher than blood. In Pan's study, ${ }^{2}$ the two groups with mean $\mathrm{BPb}$ of $67 \mu \mathrm{g} / \mathrm{dl}(\mathrm{n}=31)$ and $82 \mu \mathrm{g} / \mathrm{dl}$ $(n=33)$, showed $\mathrm{SPb}$ concentrations of $142 \%$ and $271 \%$ of $\mathrm{BPb}$. This could be caused by increased excretion of lead in saliva at these levels of $\mathrm{BPb}$, or possibly contamination during saliva collection.

The correlation of $\mathrm{SPb}$ with $\mathrm{BPb}$ in this study is not strong $(r=0.4)$. After adjusting for health condition and smoking habit of subjects, in multivariate analysis, $\mathrm{R}$ increased to 0.54 . One reason is that $\mathrm{SPb}$ may be proportional to the diffusible component of plasma lead, rather than whole blood lead. Secondly, there may be differential rates of excretion of lead into saliva at different levels of $\mathrm{BPb}$. The $r=0.4$ is stronger than what is reported among children ${ }^{4}$ and adults ${ }^{3}$ with low $\mathrm{BPb}$ levels. Collection of saliva from children is more difficult than from adults, and this could have affected the results, in addition to the small sample size $(\mathrm{n}=9)$. In the adult study, the mean BPb was $8.6 \mu \mathrm{g} / \mathrm{dl}$, which is lower than in this study. As such, these populations are not strictly comparable with our study population. Furthermore, these studies did not log transform $\mathrm{SPb}$ for statistical analysis, which could have resulted in the weaker $r$.

However, the $r$ in this study was lower than that of Pan $(r=0.8),{ }^{2}$ who noted that SPb did not show a parallel increase with BPb. The BPb levels in Pan's study population were higher than this study.

\section{Conclusion}

While the idea of measuring SPb for biological monitoring is attractive, our findings do not support its use for this purpose. 


\section{Authors' affiliations}

D Koh, V Ng, L H Chua, Y Yang, H Y Ong, S E Chia, Department of Community, Occupational and Family Medicine, Faculty of Medicine MD3, National University of Singapore, Republic of Singapore

This study was supported by a National University of Singapore Grant (R-186-000-049-2 14)

Correspondence to: Dr D Koh, Department of Community, Occupational and Family Medicine, Faculty of Medicine MD3, National University of Singapore, 16 Medical Drive, Singapore 117597, Republic of

Singapore; cofhead@nus.edu.sg

Accepted 23 September 2002

\section{REFERENCES}

1 Malamud D, Tabak L. Saliva as a diagnostic fluid. Ann N Y Acad Sci 1993;694: 1-348

2 Pan AYS. Lead levels in saliva and in blood. J Toxicol Environ Health $1981 ; 7: 273-80$.

3 Omokhodion FO, Cockford GW. Lead in sweat and its relationship to salivary and urinary levels in normal healthy subjects. Sci Tot Environ 1991; 103:113-22.

4 Fung HL, Yaffe SJ, Mattar ME, et al. Blood and salivary lead levels in children. Clin Chim Acta 1975:61:423-4.

5 DiGregorio GJ, Ferko AP, Sample RG, et al. Lead and $\delta$-aminolevulinic acid concentrations in human parotid saliva. Toxicol Appl Pharmacol 1974;27:491-3.

6 Statistical Products and Service Solutions. SPSS for Windows, version 10. Chicago: SPSS 2000.

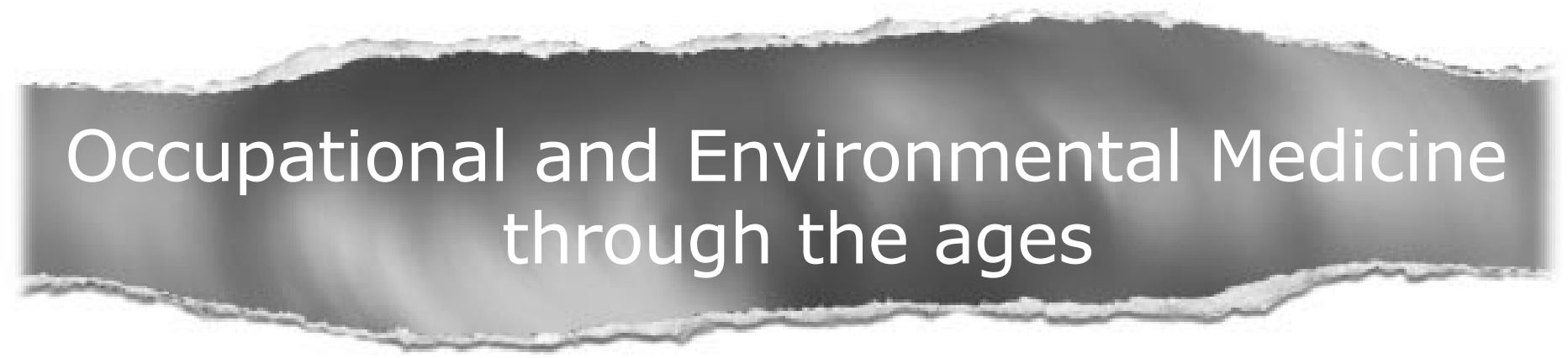

\section{Browse the Archive}

Occupational and Environmental Medicine online has an archive of content dating back to 1994. Full text from January 2000; abstracts from 1998; table of contents from 1994

\section{wWw.occenvmed.com}

